\title{
Guidelines for chemotherapy of biliary tract and ampullary carcinomas
}

\author{
Junji Furuse ${ }^{1}$, Tadahiro Takada ${ }^{2}$, Masaru Miyazaki ${ }^{3}$, Shuichi Miyakawa ${ }^{4}$, Kazuhiro Tsukada ${ }^{5}$, \\ Masato Nagino $^{6}$, Satoshi Kondo ${ }^{7}$, Hiroya Saito $^{8}$, Toshio Tsuyuguchi ${ }^{9}$, Koichi Hirata ${ }^{10}$, Fumio Kimura ${ }^{3}$, \\ Hideyuki Yoshitomi ${ }^{3}$, Satoshi Nozawa ${ }^{3}$, Masahiro Yoshida ${ }^{2}$, Keita Wada $^{2}$, Hodaka Amano ${ }^{2}$, \\ and FuMIHIKO MIURA ${ }^{2}$ \\ ${ }^{1}$ Hepatobiliary and Pancreatic Oncology Division, National Cancer Center Hospital East, 6-5-1 Kashiwanoha, Kashiwa-shi, Chiba 277-8577, \\ Japan \\ ${ }^{2}$ Department of Surgery, Teikyo University School of Medicine, Tokyo, Japan \\ ${ }^{3}$ Department of General Surgery, Chiba University Graduate School of Medicine, Chiba, Japan \\ ${ }^{4}$ Department of Gastroenterological Surgery, Fujita Health University, Toyoake, Japan \\ ${ }^{5}$ Department of Surgery and Science, Graduate School of Medicine and Pharmaceutical Science for Research, University of Toyama, Toyama, \\ Japan \\ ${ }^{6}$ Division of Surgical Oncology, Department of Surgery, Nagoya University Graduate School of Medicine, Nagoya, Japan \\ ${ }^{7}$ Department of Surgical Oncology, Hokkaido University Graduate School of Medicine, Sapporo, Japan \\ ${ }^{8}$ Department of Radiology, Asahikawa Kosei General Hospital, Asahikawa, Japan \\ ${ }^{9}$ Department of Medicine and Clinical Oncology, Chiba University Graduate School of Medicine, Chiba, Japan \\ ${ }^{10}$ Department of Surgical Oncology and Gastroenterological Surgery, Sapporo Medical University School of Medicine, Sapporo, Japan
}

\begin{abstract}
Few randomized controlled trials (RCTs) with large numbers of patients have been conducted to date in patients with biliary tract cancer, and standard chemotherapy has not been established yet. In this article we review previous studies and clinical trials regarding chemotherapy for unresectable biliary tract cancer, and we present guidelines for the appropriate use of chemotherapy in patients with biliary tract cancer. According to an RCT comparing chemotherapy and best supportive care for these patients, survival was significantly longer and quality of life was significantly better in the chemotherapy group than in the control group. Thus, chemotherapy for patients with biliary tract cancer seems to be a significant treatment of choice. However, chemotherapy for patients with biliary tract cancer should be indicated for those with unresectable, locally advanced disease or distant metastasis, or for those with recurrence after resection. That is why making the diagnosis of unresectable disease should be done with greatest care. As a rule, pathological diagnosis, including cytology or histopathological diagnosis, is preferable. Chemotherapy is recommended in patients with a good general condition, because in patients with general deterioration, such as those with a performance status of 2 or 3 or those with insufficient biliary decompression, the benefit of chemotherapy is limited. As chemotherapy for unresectable biliary tract cancer, the use of gemcitabine or tegafur/gimeracil/oteracil potassium is recommended. As postoperative adjuvant chemotherapy, no effective adjuvant therapy has been established at the present time. It is recommended that further clinical trials, especially large multi-institutional RCTs (phase III studies) using novel agents such as gemcitabine should be performed as soon as possible in order to establish a standard treatment.
\end{abstract}

Offprint requests to: J. Furuse

Received: October 1, 2007 / Accepted: October 22, 2007
Key words Biliary tract cancer - Systemic chemotherapy Adjuvant chemotherapy $\cdot$ Guidelines

\section{Introduction}

Chemotherapy in patients with biliary tract cancer is indicated in those with unresectable advanced cancer and patients with recurrence after resection. However, no standard chemotherapy for biliary tract cancer has yet been established, because few randomized controlled trials (RCTs) with large numbers of patients have been conducted to date. There are a number of studies regarding chemotherapy for biliary tract cancer, but many of these studies were prospective clinical trials with small numbers of patients, corresponding to phase II studies, or retrospective studies, so high-level evidence in this area is limited. According to the "Classification of Biliary Tract Carcinoma", bile duct cancer, gallbladder cancer, and ampullary cancer are classified as biliary tract cancer, and there are some clinical trials and articles in which treatment results that include those in intrahepatic bile duct cancer are also reported. If clinical trials are conducted for individual diseases separately, difficulties are encountered in view of efficiency and implementation, and so far, clinical trials of chemotherapy have been carried out only for biliary tract cancer in general. However, because treatment policy, sensitivity to chemotherapy, and prognosis differ widely from disease to disease, the treatment results of chemotherapy in biliary tract cancer should be evaluated on the basis of a full understanding of individual background factors.

In the present guidelines, chemotherapy for unresectable biliary tract cancer and postoperative adjuvant 
chemotherapy has been described based on results from clinical trials and retrospective studies performed up to now. In order that effective chemotherapy for biliary tract cancer may be developed, active implementation of clinical trials is recommended. Also, large multiinstitutional RCTs (phase III) should be conducted to establish standard treatment as soon as possible.

The only procedure in biliary cancer that confers a cure is curative surgical resection, so a diagnosis of incurability should be made with caution. Lest the cancer be benign, surgical treatment should be administered as a rule only after pathological diagnosis (such as cytological and histological diagnoses) has been made. The chemotherapy described in the these Guidelines is concerned with adenocarcinoma, which has the highest frequency of occurrence, so pertinent literature should be referred to in selecting treatment methods for other specific pathological types of cancer. In these Guidelines, clinical questions (CQs) are posed, with responses in the form of recommendations (grades of the recommendations are defined in Table $1^{1}$ ). Also, levels of evidence are given (in parentheses) for findings in reference citations (see definitions of levels in Table $2^{1}$ ).

CQ 1 Does chemotherapy have any benefits in patients with unresectable biliary tract cancer?

\section{Chemotherapy is recommended in patients with good general physical condition (recommendation C1).}

To assess the efficacy of chemotherapy in achieving prolonged survival in biliary tract cancer, verification is necessary by comparing it with supportive treatment

Table 1. Strength of recommendations ${ }^{1}$

A, Strongly recommend performing the clinical action

$\mathrm{B}$, Recommend performing the clinical action

$\mathrm{C} 1$, The clinical action may be considered although there is a lack of high-level scientific evidence for its use. May be useful

C2, Clinical action not definitively recommended because of insufficient scientific evidence. Evidence insufficient to support or deny usefulness

$\mathrm{D}$, Recommend not performing the clinical action alone. To date, only two small RCTs (level II) have been published. ${ }^{2,3}$

An RCT on chemotherapy and supportive treatment was conducted in patients with unresectable pancreas cancer and biliary tract cancer. ${ }^{2}$ In this study, fluorouracil (5-FU) + leucovorin or 5-FU + leucovorin + etoposide were used for chemotherapy. For all the patients, significantly prolonged survival was observed in the group who received chemotherapy (median survival time [MST], 6.0 months) compared with the group who received supportive treatment alone (MST, 2.5 months). However, due to the small number of patients with biliary tract cancer (37 patients), no significant difference was established between the groups (chemotherapy group MST, 6.5 months; supportive treatment group, 2.5 months; $P=0.1$ ). The rate of improvement in quality of life (QOL) was also examined in this trial, and a significant difference was found in the chemotherapy group compared with the supportive treatment group $(P<0.01)$; an improvement of $36 \%$ was observed in the chemotherapy group (pancreas cancer, 38\%; biliary tract cancer, $33 \%$ ) and an improvement of $10 \%$ (pancreas cancer, $13 \%$; biliary tract cancer, $5 \%$ ) was shown in the supportive treatment group.

The other small $\mathrm{RCT}^{3}$ was conducted in Japan, comparing chemotherapy with 5-FU + doxorubicin + mitomycin C (FAM) and palliative treatment, such as bypass, in patients with unresectable pancreatic cancer, gallbladder cancer, and bile duct cancer. No significant improvement in prognosis was achieved in either group, but in the patients with gallbladder cancer, a good prognosis was achieved in the chemotherapy group (level II).

A retrospective analysis comparing chemotherapy and supportive treatment in patients with gallbladder cancer was carried out. No survival benefit owing to chemotherapy was observed in patients with a performance status of 2, while prolonged survival in the chemotherapy group was observed in patients with a performance status of 0 or $1^{4}$ (level IV).

Concerning the efficacy of chemotherapy for unresectable biliary tract cancer, no evidence based on an RCT with a large number of patients is available, but there are reports demonstrating the efficacy of chemotherapy in achieving improved QOL and prolonged survival. Thus, the strength of the recommendation for chemotherapy was determined as $\mathrm{C} 1 .^{2-4}$

Table 2. Levels of evidence ${ }^{1}$

\begin{tabular}{ll}
\hline Level I & Systematic review/meta-analysis \\
Level II & One or more randomized clinical trials \\
Level III & Nonrandomized controlled trials \\
Level IV & Analytic epidemiology (cohort studies and case-control studies) \\
Level V & Descriptive study (case reports and case-series studies) \\
Level VI & $\begin{array}{l}\text { Opinions of expert panels and individual experts not based on } \\
\text { patient's data }\end{array}$ \\
\hline
\end{tabular}


Table 3. Systemic chemotherapy with single agents for biliary tract cancer

\begin{tabular}{|c|c|c|c|c|c|c|c|c|}
\hline Agent & $n$ & $\begin{array}{l}\text { Response } \\
\text { rate }\end{array}$ & MST (months) & Study design & $\begin{array}{l}\text { Evidence } \\
\text { level }\end{array}$ & Author & Year & Reference \\
\hline \multicolumn{9}{|l|}{ Fluorouracil } \\
\hline 5-FU & 18 & $0 \%$ & - & $\mathrm{RCT}$ & Level II & Takada & 1994 & 19 \\
\hline 5-FU/LV/HU & 30 & $30 \%$ & 8.0 & Cohort study & Level III & Gebbia & 1996 & 22 \\
\hline 5-FU/ $\alpha-\mathrm{IFN}$ & 32 & $34 \%$ & 12.0 & Cohort study & Level III & Patt & 1996 & 23 \\
\hline 5-FU/LV & 18 & $33 \%$ & 7.0 & Cohort study & Level III & Chen & 1998 & 24 \\
\hline 5-FU/LV & 28 & $32 \%$ & 6.0 & Cohort study & Level III & Choi & 2000 & 25 \\
\hline 5-FU/FA & 30 & $7 \%$ & 14.8 & Cohort study & Level III & Malik & 2003 & 26 \\
\hline UFT/LV & 13 & $0 \%$ & 6.5 & Cohort study & Level III & Mani & 1999 & 5 \\
\hline UFT/LV & 16 & $0 \%$ & 4.5 & Cohort study & Level III & Chen & 2003 & 6 \\
\hline Capecitabine & 26 & $19 \%$ & $\mathrm{CC}, 8.1 ; \mathrm{GB}, 9.9$ & Cohort study & Level III & Patt & 2004 & 27 \\
\hline$S-1$ & 19 & $21 \%$ & 8.3 & Cohort study & Level III & Ueno & 2004 & 28 \\
\hline UFT & 19 & $5 \%$ & 8.8 & Cohort study & Level III & Ikeda & 2005 & 7 \\
\hline S-1 & 40 & $30 \%$ & 9.4 & Cohort study & Level III & Furuse & in press & 9 \\
\hline \multicolumn{9}{|l|}{ Taxanes } \\
\hline Paclitaxel & 15 & $0 \%$ & - & Cohort study & Level III & Jones & 1996 & 29 \\
\hline Docetaxel & 16 & $0 \%$ & - & Cohort study & Level III & Pazdur & 1999 & 30 \\
\hline Docetaxel & 24 & $20 \%$ & 8.0 & Cohort study & Level III & Papakostas & 2001 & 31 \\
\hline \multicolumn{9}{|l|}{ Gemcitabine } \\
\hline Gemcitabine $\left(800 \mathrm{mg} / \mathrm{m}^{2}\right)$ & 30 & $30 \%$ & 14.0 & Cohort study & Level III & Tsavaris & 2004 & 32 \\
\hline Gemcitabine $\left(1000 \mathrm{mg} / \mathrm{m}^{2}\right)$ & 25 & $36 \%$ & 7.0 & Cohort study & Level III & Gallardo & 2001 & 33 \\
\hline Gemcitabine $\left(1000 \mathrm{mg} / \mathrm{m}^{2}\right)$ & 24 & $13 \%$ & 7.2 & Cohort study & Level III & Lin & 2003 & 34 \\
\hline Gemcitabine $\left(1000 \mathrm{mg} / \mathrm{m}^{2}\right)$ & 40 & $18 \%$ & 7.6 & Cohort study & Level III & Okusaka & 2006 & 8 \\
\hline Gemcitabine $\left(1200 \mathrm{mg} / \mathrm{m}^{2}\right)$ & 19 & $16 \%$ & 6.5 & Cohort study & Level III & Raderer & 1999 & 35 \\
\hline Gemcitabine $\left(1500 \mathrm{mg} / \mathrm{m}^{2}\right)$ & 15 & $0 \%$ & 4.6 & Cohort study & Level III & Eng & 2004 & 36 \\
\hline Gemcitabine $\left(2200 \mathrm{mg} / \mathrm{m}^{2}\right)$ & 32 & $22 \%$ & 11.5 & Cohort study & Level III & Penz & 2001 & 27 \\
\hline \multicolumn{9}{|l|}{ Others } \\
\hline Mitomycin C & 30 & $10 \%$ & 4.5 & Cohort study & Level III & Taal & 1993 & 38 \\
\hline Cisplatin & 13 & $8 \%$ & 5.5 & Cohort study & Level III & Okada & 1994 & 39 \\
\hline Irinotecan & 36 & $8 \%$ & 6.1 & Cohort study & Level III & Alberts & 2002 & 40 \\
\hline Erlotinib & 42 & $8 \%$ & 7.5 & Cohort study & Level III & Philip & 2006 & 14 \\
\hline
\end{tabular}

MST, median survival time; 5-FU, 5-fluorouracil; IFN, interferon; LV, levofolinic acid (leucovorin); FA, folinic acid; HU, hydroxyurea; CC, cholangiocarcinoma; GB gallbladder

The use of chemotherapy for biliary tract cancer should be limited to patients with unresectable, locally advanced disease and distant metastasis, or those with recurrence after resection. Chemotherapy is recommended in patients with a good general condition. However, in patients with general deterioration (performance status of 2 or 3 ) or those with insufficient biliary decompression, the benefit of chemotherapy is small, so care should be taken in considering its indications. In these patients, palliative treatment targeting the maintenance of QOL should be administered, including pain control and the placement of stents in the bile duct.

CQ 2 What is a recommended chemotherapy regimen?

As chemotherapy for unresectable advanced biliary tract carcinoma, gemcitabine or tegafur/gimeracil/ oteracil potassium is recommended (recommendation C1).
Table 3 shows the results of systemic chemotherapy with a single agent for biliary tract cancer. The single use of fluoropyrimidines such as 5-FU, or a combination of 5-FU with interferon, leucovorin, or hydroxyurea as biochemical modulators, was often used for advanced biliary tract cancer. A favorable response rate of more than $30 \%$ has been reported with the combined use of a single agent with these modulators, but no difference was observed in MST, which ranged from 7 to 12 months, in studies in patients undergoing chemotherapy for unresectable biliary tract cancer, compared with patients who received best supportive care (level III). In Japan, uracil-tegafur (UFT) is approved by the Ministry of Health, Labor, and Welfare for biliary tract cancer. However, regimens of UFT alone or UFT plus leucovorin were reported to have objective responses of $5 \%$ and $0 \%$, respectively, and more than $60 \%$ patients were evaluated as having progressive disease in these regimen. Therefore, UFT should not be used alone for biliary tract cancer (level III). 
Table 4. Combination chemotherapy for biliary tract cancer

\begin{tabular}{|c|c|c|c|c|c|c|c|c|}
\hline Regimen & $n$ & $\begin{array}{l}\text { Response } \\
\text { rate }\end{array}$ & $\begin{array}{c}\text { MST } \\
\text { (months) }\end{array}$ & Study design & $\begin{array}{c}\text { Evidence } \\
\text { level }\end{array}$ & Author & Year & Reference \\
\hline \multicolumn{9}{|l|}{ 5-FU-based } \\
\hline 5-FU/ADM/MMC (FAM) & 14 & $29 \%$ & 8.5 & Cohort study & Level III & Harvey & 1984 & 41 \\
\hline EPI/MTX/5-FU/LV & 17 & $0 \%$ & 9.0 & Cohort study & Level III & Kajanti & 1994 & 42 \\
\hline 5-FU/LV/MMC & 20 & $25 \%$ & 9.5 & Cohort study & Level III & Raderer & 1999 & 35 \\
\hline MMC/5-FU/LV & 19 & $26 \%$ & 6.0 & Cohort study & Level III & Chen & 2001 & 43 \\
\hline \multicolumn{9}{|l|}{ Platinum-based } \\
\hline $\mathrm{EPI} / \mathrm{CDDP} / 5-\mathrm{FU}(\mathrm{ECF})$ & 20 & $40 \%$ & 11.0 & Cohort study & Level III & Ellis & 1995 & 44 \\
\hline CDDP/EPI/5-FU (CEF) & 37 & $19 \%$ & 5.9 & Cohort study & Level III & Morizane & 2003 & 45 \\
\hline 5-FU/CDDP & 25 & $24 \%$ & 10.0 & Cohort study & Level III & Ducreux & 1998 & 46 \\
\hline 5-FU/CDDP/LV & 29 & $34 \%$ & 9.5 & Cohort study & Level III & Taieb & 2002 & 47 \\
\hline Capecitabine/CDDP & 42 & $21 \%$ & 9.1 & Cohort study & Level III & Kim TW & 2003 & 48 \\
\hline CDDP/IFN/DXR/5-FU (PIAF) & 38 & $21 \%$ & 14.0 & Cohort study & Level III & Patt & 2001 & 49 \\
\hline $\mathrm{EPI} / \mathrm{CDDP} / \mathrm{UFT} / \mathrm{LV}$ & 40 & $23 \%$ & 7.9 & Cohort study & Level III & Park KH & 2005 & 50 \\
\hline EPI/CDDP/capecitabine & 43 & $40 \%$ & 8.0 & Cohort study & Level III & Park SH & 2006 & 51 \\
\hline 5-FU/LV/Carboplatin & 14 & $21 \%$ & 5.0 & Cohort study & Level III & Sanz-Altamira & 1998 & 52 \\
\hline 5-FU/LV/Oxaliplatin (FOLFOX) & 16 & $19 \%$ & 9.5 & Cohort study & Level III & Nehls & 2002 & 53 \\
\hline \multicolumn{9}{|l|}{ Gemcitabine-based } \\
\hline Gemcitabine/Docetaxel & 43 & $9 \%$ & 11.0 & Cohort study & Level III & Kuhn & 2002 & 54 \\
\hline Gemcitabine/5-FU & 27 & $33 \%$ & 5.3 & Cohort study & Level III & Knox & 2004 & 55 \\
\hline Gemcitabine/5-FU/LV & 42 & $12 \%$ & 4.7 & Cohort study & Level III & $\mathrm{Hsu}$ & 2004 & 56 \\
\hline Gemcitabine/5-FU/LV & 42 & $12 \%$ & 9.7 & Cohort study & Level III & Alberts & 2005 & 57 \\
\hline Gemcitabine/CDDP & 30 & $38 \%$ & 4.6 & Cohort study & Level III & Doval & 2004 & 10 \\
\hline Gemcitabine/CDDP & 40 & $28 \%$ & 8.4 & Cohort study & Level III & Thongprasert & 2005 & 11 \\
\hline Gemcitabine/CDDP & 29 & $35 \%$ & 11.0 & Cohort study & Level III & Kim ST & 2006 & 12 \\
\hline Gemcitabine/CDDP & 27 & $33 \%$ & 10.0 & Cohort study & Level III & Park BK & 2006 & 13 \\
\hline Gemcitabine/oxaliplatin & 33 & $33 \%$ & 15.4 & Cohort study & Level III & Andre & 2004 & 58 \\
\hline Gemcitabine/capecitabine & 45 & $31 \%$ & 14.0 & Cohort study & Level III & Knox & 2005 & 16 \\
\hline Gemcitabine/capecitabine & 45 & $32 \%$ & 14.0 & Cohort study & Level III & Cho & 2005 & 59 \\
\hline
\end{tabular}

MST, median survival time; MTX, methotrexate; MMC, Mitomycin C; 5-FU, 5-fluorouracil; LV, leucovorin; IFN, interferon

\section{Side memo}

In Japan, none of the above modulators are approved by the Ministry of Health, Labour, and Welfare for use as chemotherapeutic drugs in biliary tract cancer.

Since 1999, clinical trials have been conducted with gemcitabine. Although methods of administration are different, relatively good results are reported (Table 3 ). A clinical trial (phase II) was carried out with gemcitabine alone in Japan. ${ }^{8}$ A response rate of $17.5 \%(95 \%$ confidence intervals [CI], 7.3\%-32.8\%), and an MST of 7.6 months was achieved with the standard dosage, which was $1000 \mathrm{mg} / \mathrm{m}^{2}$ as a 30-min intravenous infusion weekly, given for 3 consecutive weeks, followed by a week of rest, the results being roughly similar to those of reports from abroad. Toxicity inducing myelosuppression, such as leucopenia, as well as nausea and anorexia, was mainly observed, but tolerance was good. Based on these results, gemcitabine was approved by the Ministry of Health, Labour, and Welfare, in June, 2006, for use in biliary tract cancer (level III).
A clinical trial of tegafur/ gimeracil/oteracil potassium (S-1), which is an oral anticancer drug that consists of tegafur (FT) as a prodrug of 5-FU, 5-chloro-2, 4dihydroxypyridine (CDHP), and potassium oxonate (Oxo), was conducted in Japan. S-1 was orally administered at a dose of $80 \mathrm{mg} / \mathrm{m}^{2}$ per day for 28 days, followed by 14 days of rest. In a late phase II trial, a favorable result was reported, with a success rate of $35 \%$ and MST of 9.4 months in 40 patients. Because of this result, insurance coverage for the use of this agent for biliary tract cancer was endorsed in August, 2007 (level III).

There are also some reports of the use of mitomycin C, cisplatin, taxanes, and irinotecan (CPT-11) (Table 3), but no satisfactory result has been achieved (level III).

For biliary tract cancer, there is a limitation in treatment effects brought about by chemotherapy with the use of a single agent, so many modalities of combination chemotherapy have been carried out (Table 4). Compared with single-agent chemotherapy, the response rate of combination chemotherapy is generally high and the survival period is also inclined to be long. Although a regimen of a combination of 5-FU, anthracycline, and platinum has often been employed, no standard regimen has been established. An attempt at a regimen focusing 
Table 5. Randomized clinical trials for unresectable biliary tract cancer

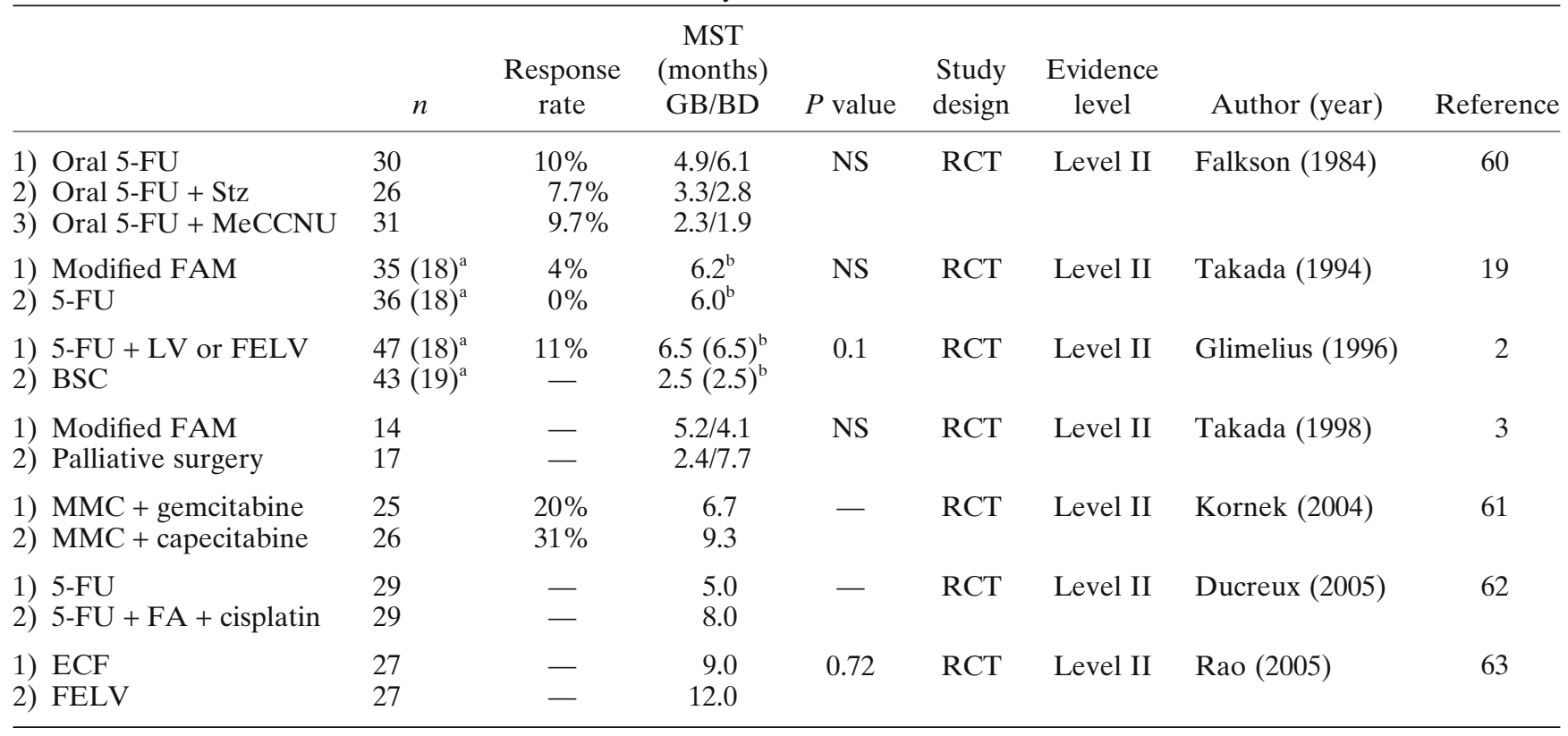

MST, median survival time; GB, gallbladder; BD, bile duct; Stz, streptozotocin; MeCCNU, methyl-CCNU; LV, levofolinic acid (lecovorin); BSC, best supportive care; MMC, mitomycin C; FA, folinic acid; FAM, 5-FU + adriamycin + MMC; FELV, 5-FU + etoposide + leucovorin; ECF, epirubicin + cisplatin + 5-FU

${ }^{\mathrm{a}}$ The total number of patients in the study, including those with pancreatic cancer; numbers in parentheses, numbers of patients with biliary tract cancer

${ }^{\mathrm{b}}$ The median overall survival time in all patients in the study, including those with pancreatic cancer; numbers in parentheses, median overall survival times in patients with biliary tract cancer

on the use of gemcitabine is currently being made and a favorable result has been achieved, with the response rate being $21 \%-48 \%$ and MST, 4.6-11.0 months in patients treated with gemcitabine + cisplatin $^{10-13}$ (level III). Currently, a large controlled trial comparing gemcitabine alone and gemcitabine + cisplatin (CDDP) is being conducted chiefly by an English group and it is drawing attention. Also, therapeutic drugs targeting molecular biological characteristics (molecular targeting therapy) are now under development. In view of a report suggesting the strong expression of epithelial growth factor receptor (EGFR) in biliary tract cancer, a phase II trial using erlotinib, which is an EGFRinhibiting drug, is being carried out. ${ }^{14}$

In biliary tract cancer, treatment results differ widely depending upon the site of the cancer. In clinical trials, patients' backgrounds, particularly the proportions of those with gallbladder cancer, bile duct cancer, and ampullary cancer, have a big impact on treatment results, such as the survival period. ${ }^{7,15,16}$ In a phase II study of gemcitabine + capecitabine, the MST in patients with gallbladder cancer was 6.6 months and the MST in patients with bile duct cancer was 19 months; thus, this difference in MST was assumed to be due to a biological difference. ${ }^{16}$ In overseas clinical trials of chemotherapy for biliary tract cancer, intrahepatic cholangiocarcinoma is often included. In Japan, however, intrahepatic cholangiocarcinoma was often excluded from clinical trials of biliary tract cancer, because this entity is classified as primary liver cancer in the "General rules for the clinical and pathological study of primary liver cancer, ${ }^{17}$ " published by the Liver Cancer Study Group of Japan ${ }^{18}$ and the "TNM classification of malignant tumours," published by the International Union Against Cancer. Also, some clinical trials include ampullary cancer and some do not. Ideally, clinical trials of chemotherapy for biliary tract cancer and the assessment of treatment results should be carried out independently according to the individual diseases, but due to the small numbers of patients with the individual diseases, making an analysis of diseases independently is difficult. Therefore, RCTs with large numbers of patients and adequate stratification of all patients concerned should be conducted to evaluate the results of chemotherapy.

The number of RCTs that have been conducted concerning chemotherapy for bile duct cancer is not so large. Outlined in Table 5 are RCTs retrieved from a literature search. In Japan, comparisons were made by Takada et al. ${ }^{3,19}$ between FAM and 5-FU alone and between FAM and palliative treatment, such as bypass operation. No significant difference in survival was confirmed in these RCTs, and a standard chemotherapy has not been established yet (level II). 
As chemotherapy for biliary tract cancer at the present time, gemcitabine or S-1, which is covered by insurance in Japan, is recommended on the basis of the results of many phase II trials, including those performed in Japan (level III). Evidence-based standard treatment should be established in the future by conducting controlled trials with the use of these agents.

\section{CQ 3 Does adjuvant chemotherapy after surgery} have a survival benefit?

No recommendable regimen is available now, but it is hoped that adjuvant chemotherapy can be carried out as a clinical trial. (recommendation C1).

In gallbladder and bile duct cancers, early recurrence often occurs even if these patients have received curative resection; the prognosis in patients with recurrence is extremely poor. Therefore, further development of effective measures for preventing recurrence through postoperative adjuvant therapy is eagerly anticipated. In view of the low incidence of biliary tract cancer in Western countries, where a large number of clinical studies of postoperative adjuvant therapy have been conducted in other types of cancer, few RCTs of postoperative adjuvant therapy for biliary tract cancer have been carried out. On the other hand, in the East Asian region (including Japan), the incidence of biliary tract cancer is high so RCTs of postoperative adjuvant therapy have been carried out in Japan.

From 1986 to 1992, Takada et al. performed an RCT in which 508 patients with pancreas cancer and biliary tract cancer were assigned to a group in which combination chemotherapy using 5-FU and mitomycin C (MMC) was administered (MF group) and a group for whom surgery alone was conducted (control group); the results were reported with a postoperative follow-up period of 5 years. ${ }^{20}$ As eligible patients, 158 patients with pancreatic cancer, 118 patients with bile duct cancer, 112 patients with gallbladder cancer, and 48 patients with ampullary cancer were chosen. Analysis was done independently in the individual diseases, and the 5-year survival rate was found to be significantly better in the MF group for gallbladder cancer (Table 6) (level II). However, according to a review of the degree of cure due to resection, a significant difference in survival rate was found only in patients with noncurative resection. On the basis of an intent-to-treat analysis, no significant difference between the MF and the control group was observed in patients with gallbladder cancer. MF therapy has not yet been established as standard postoperative adjuvant therapy in biliary tract cancer, but the efficacy
Table 6. Randomized clinical trial of adjuvant chemotherapy for pancreas and biliary tract cancer ${ }^{20}$

\begin{tabular}{|c|c|c|c|}
\hline & $n$ & 5-Year survival rate & $P$ value \\
\hline Pancreas & & & \multirow{3}{*}{ NS } \\
\hline Mitomycin C/5-FU & 81 & $11.5 \%$ & \\
\hline Surgery alone & 77 & $18.0 \%$ & \\
\hline Gallbladder & & & \multirow{3}{*}{0.037} \\
\hline Mitomycin C/5-FU & 69 & $26.0 \%$ & \\
\hline Surgery alone & 43 & $14.4 \%$ & \\
\hline Biliary tract & & & \multirow{3}{*}{ NS } \\
\hline Mitomycin C/5-FU & 58 & $26.7 \%$ & \\
\hline Surgery alone & 60 & $24.1 \%$ & \\
\hline Ampulla of Vater & & & \multirow{3}{*}{ NS } \\
\hline Mitomycin C/5-FU & 24 & $28.1 \%$ & \\
\hline Surgery alone & 24 & $34.3 \%$ & \\
\hline
\end{tabular}

of postoperative adjuvant therapy is suggested by such trials.

Todoroki summarized the results of clinical trials of chemotherapy for gallbladder cancer and verified that postoperative chemotherapy was efficacious. Most of these clinical trials were conducted using a single arm, so no regimen could be selected as a possible candidate for postoperative adjuvant therapy. ${ }^{21}$ Recently, chemotherapy focusing on gemcitabine for unresectable biliary tract cancer has been conducted, and regimens with good anticancer effects have sometimes been observed. However, no large RCTs of postoperative adjuvant therapy have been carried out with the use of such regimens. RCTs of postoperative adjuvant therapy, using new agents including gemcitabine and $\mathrm{S}-1$, should be conducted vigorously. At the present time, no recommendable postoperative adjuvant therapy has been discovered, so clinical trials of various forms of chemotherapy are anticipated in the future.

Acknowledgment. We would like to express our deep gratitude to the members of the the Japanese Association of Biliary Surgery, the Japanese Society of HepatoBiliary-Pancreatic Surgery, and the Japan Society of Clinical Oncology, who provided us with great support and guidance in the preparation of the Guidelines. This process was conducted as part of the Integrated Research Project for Assessing Medical Technology 2005 and 2006 sponsored by the Japanese Ministry of Health, Labour, and Welfare.

We truly appreciate the following active working members who developed the draft of the evidencebased clinical practice Guidelines for the treatment of biliary tract cancer (Japanese version, 2007): Masahiro Kai (Miyazaki), Yasutoshi Kimura (Sapporo), Shigeaki Sawada (Toyama), Hiroaki Shimizu (Chiba), Hisatoshi Nakagawara (Kanazawa), Kohei Nakachi (Kashiwa), and Hiroyuki Yoshitome (Chiba). We also 
appreciate very much the following members who reviewed and approved the final Japanese version of the guidelines: Hiromitsu Saisyo (Ichikawa), Munemasa Ryu (Chiba), Satoru Shikata (Kyoto), and Yuji Nimura (Nagoya).

\section{References}

1. Takada T, Miyazaki M, Miyakawa S, Tsukada K, Nagino M, Kondo $\mathrm{S}$, et al. Purpose, use, and preparation of clinical practice guidelines for the management of biliary tract and ampullary carcinomas. J Hepatobiliary Pancreat Surg 2008;15:2-6.

2. Glimelius B, Hoffman K, Sjödén PO, Jacobsson G, Sellström H, Enander LK, et al. Chemotherapy improves survival and quality of life in advanced pancreatic and biliary cancer. Ann Oncol 1996;7:593-600.

3. Takada $T$, Nimura $Y$, Katoh $H$, Nagakawa $T$, Nakayama $T$, Matsushiro T, et al. Prospective randomized trial of 5-fluorouracil, doxorubicin, and mitomycin $\mathrm{C}$ for non-resectable pancreatic and biliary carcinoma: multicenter randomized trial. Hepatogastroenterology 1998;45:2020-6.

4. Ishii H, Furuse J, Yonemoto N, Nagase M, Yoshino M, Sato T. Chemotherapy in the treatment of advanced gallbladder cancer. Oncology 2004;66:138-42.

5. Mani S, Sciortino D, Samuels B, Arrietta R, Schilsky RL, Vokes EE, et al. Phase II trial of uracil/tegafur (UFT) plus leucovorin in patients with advanced biliary carcinoma. Invest New Drugs 1999;17:97-101.

6. Chen JS, Yang TS, Lin YC, Jan YY. A phase II trial of tegafur-uracil plus leucovorin $(\mathrm{LV})$ in the treatment of advanced biliary tract carcinomas. Jpn J Clin Oncol 2003;33:353-6.

7. Ikeda M, Okusaka T, Ueno H, Morizane C, Furuse J, Ishii H. A phase II trial of Uracil-tegafur (UFT) in patients with advanced biliary tract carcinoma. Jpn J Clin Oncol 2005;35:439-43.

8. Okusaka T, Ishii H, Funakoshi A, Yamao K, Ohkawa S, Saito S, et al. Phase II study of single-agent gemcitabine in patients with advanced biliary tract cancer. Cancer Chemother Pharmacol 2006;57:647-53.

9. Furuse J, Okusaka T, Boku N, Ohkawa S, Yamao Y, Masumoto T, et al. S-1 monotherapy as first-line treatment in patients with advanced biliary tract cancer: A multicenter phase II study. Cancer Chemother Pharmacol in press.

10. Doval DC, Sekhon JS, Gupta SK, Fuloria J, Shukla VK, Gupta S, et al. A phase II study of gemcitabine and cisplatin in chemotherapy-naive, unresectable gall bladder cancer. $\mathrm{Br} \mathrm{J}$ Cancer 2004;90:1516-20.

11. Thongprasert S, Napapan S, Charoentum C, Moonprakan S. Phase II study of gemcitabine and cisplatin as first-line chemotherapy in inoperable biliary tract carcinoma. Ann Oncol 2005;16:279-81.

12. Kim ST, Park JO, Lee J, Lee KT, Lee JK, Choi SH, et al. A Phase II study of gemcitabine and cisplatin in advanced biliary tract cancer. Cancer 2006;106:1339-46.

13. Park BK, Kim YJ, Park JY, Bang S, Park SW, Chung JB, et al. Phase II study of gemcitabine and cisplatin in advanced biliary tract cancer. J Gastroenterol Hepatol 2006;21:999-1003.

14. Philip PA, Mahoney MR, Allmer C, Thomas J, Pitot HC, Kim G, et al. Phase II study of erlotinib in patients with advanced biliary cancer. J Clin Oncol 2006;24:3069-74.

15. Furuse J, Okusaka T, Funakoshi A, Yamao K, Nagase M, Ishii H, et al. Early phase II study of uracil-tegafur plus doxorubicin in patients with unresectable advanced biliary tract cancer. Jpn J Clin Oncol 2006;36:552-6.

16. Knox JJ, Hedley D, Oza A, Feld R, Siu LL, Chen E, et al. Combining gemcitabine and capecitabine in patients with advanced biliary cancer: a phase II trial. J Clin Oncol 2005;23:2332-8.
17. Liver Cancer Study Group of Japan. General rules for the clinical and pathological study of primary liver cancer. Second English Edition. Tokyo: Kanehara; 2003. p.32.

18. International Union Against Cancer. TNM classification of malignant tumours. Six Edition. Yew York: Wiley-Liss; 2002. p.81.

19. Takada T,KatoH,Matsushiro T,Nimura Y,Nagakawa T, Nakayama T. Comparison of 5-fluorouracil, doxorubicin and mitomycin $\mathrm{C}$ with 5-fluorouracil alone in the treatment of pancreatic-biliary carcinomas. Oncology 1994;51:396-400.

20. Takada T, Amano H, Yasuda H, Nimura Y, Matsushiro T, Kato H, et al. Study Group of Surgical Adjuvant Therapy for Carcinomas of the Pancreas and Biliary Tract. Is postoperative adjuvant chemotherapy useful for gallbladder carcinoma? A phase III multicenter prospective randomized controlled trial in patients with resected pancreaticobiliary carcinoma. Cancer 2002;95:168595.

21. Todoroki T. Chemotherapy for gallbladder carcinoma - a surgeon's perspective. Hepatogastroenterology 2000;47:948-55.

22. Gebbia V, Majello E, Testa A, Pezzella G, Giuseppe S, Giotta F, et al. Treatment of advanced adenocarcinomas of the exocrine pancreas and the gallbladder with 5-fluorouracil, high dose levofolinic acid and oral hydroxyurea on a weekly schedule. Results of a multicenter study of the Southern Italy Oncology Group (G.O.I.M.). Cancer 1996;78:1300-7.

23. Patt YZ, Jones DV, Hoque A, Lozano R, Markowitz A, Raijman I, et al. Phase II trial of intravenous flourouracil and subcutaneous interferon alfa-2b for biliary tract cancer. J Clin Oncol 1996; 14:2311-5.

24. Chen JS, Jan YY, Lin YC, Wang HM, Chang WC, Liau CT. Weekly $24 \mathrm{~h}$ infusion of high-dose 5-fluorouracil and leucovorin in patients with biliary tract carcinomas. Anticancer Drugs 1998;9:393-7.

25. Choi CW, Choi IK, Seo JH, Kim BS, Kim JS, Kim CD, et al. Effects of 5-fluorouracil and leucovorin in the treatment of pancreaticbiliary tract adenocarcinomas. Am J Clin Oncol 2000;23:425-8.

26. Malik IA, Aziz Z. Prospective evaluation of efficacy and toxicity of 5-fu and folinic acid (Mayo Clinic regimen) in patients with advanced cancer of the gallbladder. Am J Clin Oncol 2003; 26:124-6.

27. Patt YZ, Hassan MM, Aguayo A, Nooka AK, Lozano RD, Curley SA, et al. Oral capecitabine for the treatment of hepatocellular carcinoma, cholangiocarcinoma, and gallbladder carcinoma. Cancer 2004;101:578-86.

28. Ueno H, Okusaka T, Ikeda M, Takezako Y, Morizane C. Phase II study of S-1 in patients with advanced biliary tract cancer. Br J Cancer 2004;91:1769-74.

29. Jones DV, Lozano R, Hoque A, Markowitz A, Patt YZ. Phase II study of paclitaxel therapy for unresectable biliary tree carcinomas. J Clin Oncol 1996;14:2306-10.

30. Pazdur R, Royce ME, Rodriguez GI, Rinaldi DA, Patt YZ, Hoff $\mathrm{PM}$, et al. Phase II trial of docetaxel for cholangiocarcinoma. Am J Clin Oncol 1999;22:78-81.

31. Papakostas P, Kouroussis C, Androulakis N, Samelis G, Aravantinos G, Kalbakis K, et al. First-line chemotherapy with docetaxel for unresectable or metastatic carcinoma of the biliary tract. A multicentre phase II study. Eur J Cancer 2001;37:1833-8.

32. Tsavaris N, Kosmas C, Gouveris P, Gennatas K, Polyzos A, Mouratidou D, et al. Weekly gemcitabine for the treatment of biliary tract and gallbladder cancer. Invest New Drugs 2004;22: 193-8.

33. Gallardo JO, Rubio B, Fodor M, Orlandi L, Yáñez M, Gamargo $\mathrm{C}$, et al. A phase II study of gemcitabine in gallbladder carcinoma. Ann Oncol 2001;12:1403-6.

34. Lin MH, Chen JS, Chen HH, Su WC. A phase II trial of gemcitabine in the treatment of advanced bile duct and periampullary carcinomas. Chemotherapy 2003;49:154-8.

35. Raderer M, Hejna MH, Valencak JB, Kornek GV, Weinländer GS, Bareck E, et al. Two consecutive phase II studies of 5fluorouracil/leucovorin/mitomycin $\mathrm{C}$ and of gemcitabine in patients with advanced biliary cancer. Oncology 1999;56:177-80. 
36. Eng C, Ramanathan RK, Wong MK, Remick SC, Dai L, WadeOliver KT, et al. A Phase II trial of fixed dose rate gemcitabine in patients with advanced biliary tree carcinoma. Am J Clin Oncol 2004;27:565-9.

37. Penz M, Kornek GV, Raderer M, Ulrich-Pur H, Fiebiger W, Lenauer A, et al. Phase II trial of two-weekly gemcitabine in patients with advanced biliary tract cancer. Ann Oncol 2001; 12:183-6.

38. Taal BG, Audisio RA, Bleiberg H, Blijham GH, Neijt JP, Veenhof $\mathrm{CH}$, et al. Phase II trial of mitomycin $\mathrm{C}$ (MMC) in advanced gallbladder and biliary tree carcinoma. An EORTC Gastrointestinal Tract Cancer Cooperative Group Study. Ann Oncol 1993;4: $607-9$.

39. Okada S, Ishii H, Nose H, Yoshimori M, Okusaka T, Aoki K, et al. A phase II study of cisplatin in patients with biliary tract carcinoma. Oncology 1994;51:515-7.

40. Alberts SR, Fishkin PA, Burgart LJ, Cera PJ, Mahoney MR, Morton RF, et al. CPT-11 for bile-duct and gallbladder carcinoma: a phase II North Central Cancer Treatment Group (NCCTG) study. Int J Gastrointest Cancer 2002;32:107-14.

41. Harvey JH, Smith FP, Schein PS. 5-Fluorouracil, mitomycin, and doxorubicin (FAM) in carcinoma of the biliary tract. J Clin Oncol 1984;2:1245-8.

42. Kajanti M, Pyrhonen S. Epirubicin-sequential methotrexate-5fluorouracil-leucovorin treatment in advanced cancer of the extrahepatic biliary system. A phase II study. Am J Clin Oncol 1994;17:223-6.

43. Chen JS, Lin YC, Jan YY, Liau CT. Mitomycin C with weekly 24-h infusion of high-dose 5-fluorouracil and leucovorin in patients with biliary tract and periampullar carcinomas. Anticancer Drugs 2001;12:339-43.

44. Ellis PA, Norman A, Hill A, O'Brien ME, Nicolson M, Hickish T, et al. Epirubicin, cisplatin and infusional 5-fluorouracil (5-FU) (ECF) in hepatobiliary tumours. Eur J Cancer 1995;31A:1594-8.

45. Morizane C, Okada S, Okusaka T, Ueno H, Saisho T. Phase II study of cisplatin, epirubicin, and continuous-infusion 5fluorouracil for advanced biliary tract cancer. Oncology 2003; 64:475-6.

46. Ducreux M, Rougier P, Fandi A, Clavero-Fabri MC, Villing AL, Fassone F, et al. Effective treatment of advanced biliary tract carcinoma using 5-fluorouracil continuous infusion with cisplatin. Ann Oncol 1998;9:653-6.

47. Taïeb J, Mitry E, Boige V, Artru P, Ezenfis J, Lecomte T, et al. Optimization of 5-fluorouracil (5-FU)/cisplatin combination chemotherapy with a new schedule of leucovorin, 5-FU and cisplatin (LV5FU2-P regimen) in patients with biliary tract carcinoma. Ann Oncol 2002;13:1192-6.

48. Kim TW, Chang HM, Kang HJ, Lee JR, Ryu MH, Ahn JH, et al. Phase II study of capecitabine plus cisplatin as first-line chemotherapy in advanced biliary cancer. Ann Oncol 2003;14:1115-20.

49. Patt YZ, Hassan MM, Lozano RD, Waugh KA, Hoque AM, Frome $\mathrm{AI}$, et al. Phase II trial of cisplatin, interferon alpha-2b, doxorubicin, and 5-fluorouracil for biliary tract cancer. Clin Cancer Res 2001;7:3375-80.

50. Park KH, Choi IK, Kim SJ, Oh SC, Seo JH, Choi CW, et al. The efficacy of epirubicin, cisplatin, uracil/tegafur, and leucovorin in patients with advanced biliary tract carcinoma. Cancer 2005;103: 2338-43.

51. Park SH, Park YH, Lee JN, Bang SM, Cho EK, Shin DB, et al. Phase II study of epirubicin, cisplatin, and capecitabine for advanced biliary tract adenocarcinoma. Cancer 2006;106:361-5.

52. Sanz-Altamira PM, Ferrante K, Jenkins RL, Lewis WD, Huberman MS, Stuart KE. A phase II trial of 5-fluorouracil, leucovorin, and carboplatin in patients with unresectable biliary tree carcinoma. Cancer 1998;82:2321-5.

53. Nehls O, Klump B, Arkenau HT, Hass HG, Greschniok A, Gregor $\mathrm{M}$, et al. Oxaliplatin, fluorouracil and leucovorin for advanced biliary system adenocarcinomas: a prospective phase II trial. Br J Cancer 2002;87:702-4.

54. Kuhn R, Hribaschek A, Eichelmann K, Rudolph S, Fahlke J, Ridwelski K. Outpatient therapy with gemcitabine and docetaxel for gallbladder, biliary, and cholangio-carcinomas. Invest New Drugs 2002;20:351-6.

55. Knox JJ, Hedley D, Oza A, Siu LL, Pond GR, Moore MJ. Gemcitabine concurrent with continuous infusional 5-fluorouracil in advanced biliary cancers: a review of the Princess Margaret Hospital experience. Ann Oncol 2004;15:770-4.

56. Hsu C, Shen YC, Yang CH, Yeh KH, Lu YS, Hsu CH, et al. Weekly gemcitabine plus 24-h infusion of high-dose 5-fluorouracil/leucovorin for locally advanced or metastatic carcinoma of the biliary tract. Br J Cancer 2004;90:1715-9.

57. Alberts SR, Al-Khatib H, Mahoney MR, Burgart L, Cera PJ, Flynn PJ, et al. Gemcitabine, 5-fluorouracil, and leucovorin in advanced biliary tract and gallbladder carcinoma: a North Central Cancer Treatment Group phase II trial. Cancer 2005;103:111-8.

58. André T, Tournigand C, Rosmorduc O, Provent S, MaindraultGoebel F, Avenin D, et al. Gemcitabine combined with oxaliplatin (GEMOX) in advanced biliary tract adenocarcinoma: a GERCOR study. Ann Oncol 2004;15:1339-43.

59. Cho JY, Paik YH, Chang YS, Lee SJ, Lee DK, Song SY, et al. Capecitabine combined with gemcitabine (CapGem) as first-line treatment in patients with advanced/metastatic biliary tract carcinoma. Cancer 2005;104:2753-8.

60. Falkson G, MacIntyre JM, Moertel CG. Eastern Cooperative Oncology Group experience with chemotherapy for inoperable gallbladder and bile duct cancer. Cancer 1984;54:965-9.

61. Kornek GV, Schuell B, Laengle F, Gruenberger T, Penz M, Karall $\mathrm{K}$, et al. Mitomycin $\mathrm{C}$ in combination with capecitabine or biweekly high-dose gemcitabine in patients with advanced biliary tract cancer: a randomised phase II trial. Ann Oncol 2004;15: 478-83.

62. Ducreux M, Van Cutsem E, Van Laethem JL, Gress TM, Jeziorski $\mathrm{K}$, Rougier P, et al. A randomised phase II trial of weekly highdose 5-fluorouracil with and without folinic acid and cisplatin in patients with advanced biliary tract carcinoma: results of the 40955 EORTC trial. Eur J Cancer 2005;41:398-403.

63. Rao S, Cunningham D, Hawkins RE, Hill ME, Smith D, Daniel F, et al. Phase III study of 5FU, etoposide and leucovorin (FELV) compared to epirubicin, cisplatin and 5FU (ECF) in previously untreated patients with advanced biliary cancer. $\mathrm{Br} \mathrm{J}$ Cancer 2005;92:1650-4. 